\title{
Combined Training in the Treatment of Type 2 Diabetes Mellitus: A Review
}

\author{
Cláudia Gomes Bracht1ํㅜ, Rodrigo Sudatti Delevatti², Luiz Fernando Martins Kruel${ }^{1}$ \\ ${ }^{1}$ Universidade Federal do Rio Grande do Sul, Porto Alegre, Brazil \\ ${ }^{2}$ Universidade Federal de Santa Catarina, Florianópolis, Brazil \\ Email: claudiagbracht@gmail.com
}

How to cite this paper: Bracht, C.G., Delevatti, R.S. and Kruel, L.F.M. (2017) Combined Training in the Treatment of Type 2 Diabetes Mellitus: A Review. Health, 9, 1605-1617.

https://doi.org/10.4236/health.2017.912118

Received: September 22, 2017

Accepted: November 5, 2017

Published: November 8, 2017

Copyright (c) 2017 by authors and Scientific Research Publishing Inc. This work is licensed under the Creative Commons Attribution International License (CC BY 4.0).

http://creativecommons.org/licenses/by/4.0/

\begin{abstract}
This study aimed to review combined training (CT) effects on HbAlc levels in patients with T2DM. Searches were conducted in PubMed via MEDLINE and Google Scholar. Of the 14 selected studies, 11 found reductions in HbA1c levels. The interventions that performed both aerobic and resistance training in the same sessions were highlighted. In aerobic training, the best results were in the interventions between 30 and 45 minutes per session, with intensities between 60 and $80 \%$ of maximal parameters. In resistance training, the interventions with sets from 8 to 12 repetitions with intensities of $80 \%$ and $60 \%$ of $1 \mathrm{RM}$ respectively, or prescribed by maximal repetitions, were highlighted. We conclude that CT can result in better glycaemic control than AT and RT conducted alone.
\end{abstract}

\section{Keywords}

Diabetes, Combined Training, Glycaemic Control, HbA1c

\section{Introduction}

The growth of non-communicable chronic diseases of endocrine and metabolic character has been raising great concern worldwide, and, in this context, diabetes mellitus (DM) is one of the most common diseases in almost all countries [1]. The new estimates of diabetes in the world population confirm the large burden of the disease, given that the number of diabetic people in 2015 was 422 million, and until 2030 this number is expected to exceed 640 million [2].

Type 2 diabetes mellitus (T2DM), the most common form of the disease (90\% - 95\% of the cases), results from a combination of insulin resistance with inadequate compensation of this hormone's secretion [3]. Regarding the disease treatment, the three main tools for T2DM management are exercise, diet and 
medication [4]. In relation to structured exercise, many studies were conducted and significant reductions were found in the glycaemic responses of individuals who suffer from this disease [5] [6] [7].

The glycaemic control improvement can be evidenced through the levels of glycated hemoglobin (HbAlc) [3], a measurement used for the monitoring of therapeutic interventions efficacy. Stratton et al. [8] explain that any reduction in $\mathrm{HbAlc}$ levels implies in a lower risk of complications associated to the disease. In this context, systematic reviews regarding physical exercise in T2DM patients showed that structured physical exercise is able to decrease the absolute levels of HbAlc in the blood in about 0.6\% [5] [9] [10].

Studies have been conducted searching for optimal training models which can control T2DM, preventing or at least delaying the chronic complications associated to the inadequate control of the disease. In the last decades, the different modalities and forms of manipulation of physical training have been investigated, in which beneficial effects were found with aerobic and resistance training separately performed or combined-aerobic plus resistance-[5]. However, in the meta-analysis of Schwingshackl et al. [11], a greater efficacy was found with combined training (CT) in comparison to resistance (RT) and aerobic training (AT) performed alone.

Evidencing its efficacy, there is a need to expand the discussion about manners to optimize combined training structuring for glycaemic control for T2DM patients, discussing characteristics as intervention period, weekly frequency, duration, intensity and order of the modalities. Therefore, the present study aimed to review combined training interventions and its respective effects on $\mathrm{HbAlc}$ levels in T2DM patients.

\section{Methods}

Searches were conducted in the databases MEDLINE via PubMed and Google Scholar and the following key words were used: "diabetes", "exercise", "combined", "combined training", "aerobic", "resistance", "HbAlc", "exercício", "combinado", "aeróbico", "força", brought together by means of the boolean operator "OR" and "AND". References lists of review studies were also examined to find other possible eligible studies for the present review. We included studies that performed structured combined training with T2DM patients older than 18 years old, which evaluated changes in HbAlc levels as an outcome (by means or differences between means) at baseline and after interventions, written in English and Portuguese, published between 2000 and 2015. Exclusion criteria were studies of patients with type 1 diabetes mellitus or gestational diabetes, studies that did not report information regarding the associations of the intervention with $\mathrm{HbAlc}$ levels in the experimental group or sub-studies of the included interventions.

\section{Results}

Fourteen articles [12]-[25] met the inclusion criteria. Among the eligible studies, 
most of them had a control group, except four of them [15] [20] [22] [23]. The main characteristics of the studies are presented in details in Table 1.

Of the 14 studies, most of them [12] [13] [14] [16] [17] [18] [19] [21] [23] [24] [25] randomly allocated the subjects. In relation to sex, most of the studies investigated both sexes, except only two studies [13] [15] which investigated postmenopausal women.

\section{Discussion}

The beneficial effects of structured physical training have been well documented in the last decades, presenting improvements in T2DM control, with the improvement in the glycaemic control and reduction of disease-related comorbidities [26]. For the present review, the chosen outcome of glycaemic control was HbA1c levels, which represent the mean glucose concentration in the 8-12 weeks preceding the accomplishment of clinical exams [27]. Analyzing the results of the 14 included studies, 11 found positive responses in the glycaemic control, by significant decreases in HbA1c levels [14]-[20] [22] [23] [24] [25], whereas only three studies did not find improvements in this outcome [12] [13] [21].

It is important to highlight the importance of exercise protocols structuring, because the study of Umpierre et al. [5] demonstrated that structured physical training can reduce $\mathrm{HbAlc}$ levels more expressively than only the counseling of physical exercise practice. In addition, Oliveira et al. [7] claim that combined training structuring is more efficient that the isolated modalities (aerobic or resistance), because the improvement mechanisms of glycaemic metabolism are different and synergists. Faced with the mechanistic considerations and the clinical evidences, CT has been highly recommended for the glycaemic control of T2DM patients, in which the results have been reported and discussed regarding the intervention characteristics.

\subsection{Intervention Period}

Regarding intervention period, there were studies with short periods (eight weeks) [22], as well as longer ones, with 52 weeks [14] [18] [19] [20]. Associating intervention period to the results found, a superiority of the long-term trainings is not perceived in comparison to the short-term ones, because similar reductions in HbA1c levels were shown after interventions with short periods $(0.5 \%$ eight weeks) [22] and medium terms ( $0.5 \%$ to $0.8 \%$ - 12 to 20 weeks) [15] [17], with high variability in the results with long term interventions $(0.27 \%$ to $1.21 \%$ - from 20 weeks) [14] [16] [18] [19] [20] [23] [24] [25].

Although the field of T2DM and physical training does not provide studies comparing progressive combined training versus non-progressive combined training, we believe that studies with long term interventions may not expressively impact on glycaemic control because progressions were not conducted in the volume and intensity throughout the interventions. In this sense, it is important to highlight that two [13] [21] of the three studies [12] [13] [21] without 
Table 1. Responses in combined training in T2DM patients.

\begin{tabular}{|c|c|c|c|c|}
\hline Study & Sample (n) & Period & Volume/Intensity & Results in HbA1c levels \\
\hline $\begin{array}{l}\text { Tessier et al. } \\
(2000) \text { [12] }\end{array}$ & $\begin{array}{c}\text { Both sexes } \\
\text { (CT: 19, CG: 20) }\end{array}$ & 16 weeks & $\begin{array}{c}3 \mathrm{x} / \text { week in circuit } \\
\text { AT: } 20 \mathrm{~min} \text { w/intensity progressing from } \\
35 \%-59 \% \mathrm{HR}_{\max } \text { to } 60 \%-79 \% \mathrm{HR}_{\max } \\
\text { RT: } 2 \text { sets of } 20 \text { rep (m.m.g.) }\end{array}$ & Without significant alterations \\
\hline $\begin{array}{l}\text { Cuff et al. (2003) } \\
\qquad[13]\end{array}$ & $\begin{array}{c}\text { Post-menopausal } \\
\text { women (CT:10, CG:9) }\end{array}$ & 16 weeks & $\begin{array}{c}3 \mathrm{x} / \text { week } \\
\text { Total duration of } 75 \text { min per session } \\
\text { AT: } 60 \% \text { to } 75 \% \mathrm{HR}_{\text {res }} \\
\text { RT: } 2 \text { sets of } 12 \text { rep ( } 5 \text { exercises m.m.g.) }\end{array}$ & Without significant alterations \\
\hline $\begin{array}{l}\text { Balducci et al. } \\
\text { (2004) [14] }\end{array}$ & $\begin{array}{c}\text { Both sexes } \\
\text { (CT: } 51, \text { CG: } 53)\end{array}$ & 52 weeks & $\begin{array}{c}3 \mathrm{x} / \text { week } \\
\text { AT: } 30 \text { min at } 40 \%-80 \% \mathrm{HR}_{\text {res }} \\
\text { RT: } 3 \text { sets of } 12 \text { rep at } 40 \%-60 \% 1 \mathrm{RM} \\
\text { (6 exercises m.m.g.) }\end{array}$ & $\begin{array}{l}\text { Significant alteration: } \\
\downarrow 1.21 \% \text { in comparison to } \\
\text { pre-training }\end{array}$ \\
\hline $\begin{array}{l}\text { Tokmakidis et al. } \\
\qquad \text { (2004) [15] }\end{array}$ & $\begin{array}{l}\text { Post-menopausal } \\
\text { women (CT: 9) }\end{array}$ & 16 weeks & $\begin{array}{c}\text { AT: } 2 \mathrm{x} / \text { week (Mondays and Thursdays) } \\
40-45 \mathrm{~min} \text { at } 60 \%-70 \% \mathrm{HR}_{\max } \text { progressing to } 70 \%- \\
80 \% \mathrm{HR}_{\max } \text { throughout the intervention } \\
\mathrm{RT}: 2 \mathrm{x} / \text { week (Tuesdays and Fridays) } \\
3 \text { sets of } 12 \text { repetitions at } 60 \% 1 \mathrm{RM} \text { (5 exercises } \\
\text { m.m.g.) }\end{array}$ & $\begin{array}{l}\text { Significant alteration: } \\
\downarrow 0.80 \% \text { in comparison to } \\
\text { pre-training }\end{array}$ \\
\hline $\begin{array}{c}\text { Sigal et al. (2007) } \\
{[16]}\end{array}$ & $\begin{array}{c}\text { Both sexes } \\
(\mathrm{CT}: 64, \mathrm{CG}: 63)\end{array}$ & 22 weeks & $\begin{array}{l}3 \mathrm{x} / \text { week } \\
\text { AT: duration of the sessions progressed from } \\
25 \text { to } 45 \text { min and intensity progressed from } \\
70 \text { to } 75 \% \text { of } \mathrm{HR}_{\max } \\
\text { RT: } 2 \text { to } 3 \text { sets of } 7 \text { to } 9 \mathrm{RM} \text { (7 exercises } \\
\text { - not-specified) }\end{array}$ & $\begin{array}{c}\text { Significant alteration: } \\
\downarrow 0.90 \% \text { in comparison to } \\
\text { pre-training } \\
\downarrow 0.46 \% \text { in comparison to AT } \\
\downarrow 0.59 \% \text { in comparison to RT }\end{array}$ \\
\hline $\begin{array}{l}\text { Lambers et al. } \\
\quad(2008)[17]\end{array}$ & $\begin{array}{c}\text { Both sexes } \\
(\mathrm{CT}: 17, \mathrm{CG}: 11)\end{array}$ & 12 weeks & $\begin{array}{l}3 \mathrm{x} / \text { week, in circuit: } \\
\text { Walk or light run }(10 \mathrm{~min}) \text {, elbow flexion and } \\
\text { extension, (10 min), cycling (10 min), knee flexion } \\
\text { and extension (10 min), stepping }(10 \mathrm{~min}) \text {. } \\
\text { AT: progressed from } 60 \text { to } 85 \% \text { of } \mathrm{HR}_{\mathrm{res}} \\
\text { RT: progressed from } 3 \text { series of } 10-15 \text { rep } \\
\text { from } 60 \text { to } 85 \% 1 \mathrm{RM}\end{array}$ & $\begin{array}{l}\text { Significant alteration: } \\
\downarrow 0.5 \% \text { in comparison to } \\
\text { pre-training }\end{array}$ \\
\hline $\begin{array}{l}\text { Church et al. } \\
\text { (2010) [18] }\end{array}$ & $\begin{array}{c}\text { Both sexes } \\
\text { (CT: 62, CG: 41) }\end{array}$ & 39 weeks & $\begin{array}{c}\text { AT: } 3 \mathrm{x} / \text { week. } \\
\text { Weekly dose of } 10 \mathrm{kcal} / \mathrm{kg} \text { body mass, } \\
\text { among } 50 \text { and } 80 \% \mathrm{VO}_{\max } \\
\mathrm{RT}: 2 \mathrm{x} / \text { week } \\
1 \text { set of } 10 \text { to } 12 \mathrm{RM} \text { ( } 9 \text { exercises m.m.g.) }\end{array}$ & $\begin{array}{c}\text { Significant alteration: } \\
\downarrow 0.27 \% \text { in comparison to } \\
\text { pre-training } \\
\downarrow 0.38 \% \text { in comparison to CG }\end{array}$ \\
\hline $\begin{array}{l}\text { Balducci et al. } \\
\text { (2010) [19] }\end{array}$ & $\begin{array}{c}\text { Both sexes } \\
(\mathrm{CT}: 22, \mathrm{CG}: 20)\end{array}$ & 52 weeks & $\begin{array}{c}2 \mathrm{x} / \text { week } \\
\text { AT: } 40 \mathrm{~min} \text { at } 70 \%-80 \% \mathrm{VO}_{2 \max } \\
\text { RT: } 80 \% 1 \mathrm{RM}(5 \text { exercises } \mathrm{m} . \mathrm{m} . \mathrm{g} .) \\
\text { Training volume increasing in } 0.1 \mathrm{kcal} / \mathrm{kg} \\
\text { body mass } / \text { month }\end{array}$ & $\begin{array}{l}\text { Significant alteration: } \downarrow 1.09 \% \text { in } \\
\text { comparison to pre-training and } \\
\downarrow 0.94 \text { in comparison to CG }\end{array}$ \\
\hline $\begin{array}{l}\text { Fatone et al. (2010) } \\
\qquad[20]\end{array}$ & Both sexes (CT: 8) & 52 weeks & $\begin{array}{c}2 \mathrm{x} / \text { week } \\
\text { AT: } 55 \%-70 \% \mathrm{VO}_{2 \max } \\
\text { RT: in circuit, progressing from } 2 \text { sets of } 15 \text { rep at } \\
60 \% 1 \mathrm{RM} \text {, to } 3 \text { sets of } 8 \text { rep at } 80 \% 1 \mathrm{RM} \text { (4 exercises } \\
\text { m.m.g.) }\end{array}$ & $\begin{array}{l}\text { Significant alteration: } \downarrow 0.45 \% \text { in } \\
\text { comparison to pre-training }\end{array}$ \\
\hline $\begin{array}{l}\text { Jorge et al. (2011) } \\
\qquad 21]\end{array}$ & $\begin{array}{c}\text { Both sexes } \\
(\mathrm{CT}: 12, \mathrm{CG}: 12)\end{array}$ & 12 weeks & $\begin{array}{c}3 \mathrm{x} / \text { week } \\
\text { Total duration of } 60 \text { min per session } \\
\text { AT: exercise in the cycle ergometer at } \mathrm{HR}_{\mathrm{LT}} \\
\text { RT: } 7 \text { exercises in circuit m.m.g. }\end{array}$ & Without significant alterations \\
\hline
\end{tabular}




\section{Continued}

\begin{tabular}{|c|c|c|c|c|}
\hline $\begin{array}{l}\text { Touvra et al. } \\
\text { (2011) [22] }\end{array}$ & Both sexes (CT: 10) & 8 weeks & $\begin{array}{c}4 \mathrm{x} / \text { week } \\
\text { AT: } 30 \mathrm{~min} \text { at } 70 \%-80 \% \mathrm{HR}_{\max } \\
\text { RT: } 3 \text { sets of } 15 \text { rep at } 60 \% 1 \mathrm{RM}(6 \text { exercises m.m.g.) }\end{array}$ & $\begin{array}{l}\text { Significant alterations: } \downarrow 0.50 \% \text { in } \\
\text { comparison to pre-training }\end{array}$ \\
\hline $\begin{array}{c}\text { Larose et al. (2012) } \\
\text { [23] }\end{array}$ & $\begin{array}{c}\text { Both sexes } \\
\text { (CT: } 64, \text { CG: 64) }\end{array}$ & 22 weeks & $\begin{array}{c}3 \mathrm{x} / \text { week } \\
\text { AT: progressing from } 25 \text { to } 45 \mathrm{~min} \text { at } \\
70 \%-75 \% \mathrm{HR}_{\max } \\
\text { RT: } 3 \text { sets of } 8 \text { to } 12 \mathrm{RM} \\
\text { (2 groups of } 7 \text { exercises m.m.g.) }\end{array}$ & $\begin{array}{l}\text { Significant alteration: } \\
\downarrow 1 \% \text { in comparison to } \\
\quad \text { pre-training }\end{array}$ \\
\hline $\begin{array}{l}\text { Kadoglou et al. } \\
\text { (2013) [24] }\end{array}$ & $\begin{array}{c}\text { Both sexes } \\
\text { (CT: } 22 \text {, CG: } 24)\end{array}$ & 26 weeks & $\begin{array}{c}\text { 4x /week ( } 1 \text { session of } \mathrm{AT}, 1 \text { session of } \mathrm{RT} \text { and } \\
2 \text { sessions of } \mathrm{AT} \text { and } \mathrm{RT} \text { combined) } \\
\text { Total duration of } 60 \text { min per session } \\
\text { AT: } \pm 30 \text { min at } 60 \%-75 \% \mathrm{HR}_{\max } \\
\text { RT: } 1 \text { to } 2 \text { sets of } 8 \text { to } 10 \text { repetitions at } 60 \%-80 \% \\
1 \text { RM ( } 8 \text { exercises m.m.g.) }\end{array}$ & $\begin{array}{l}\text { Significant alteration: } \\
\downarrow 0.90 \% \text { in comparison to } \\
\text { pre-training }\end{array}$ \\
\hline $\begin{array}{l}\text { Stegen et al. (2015) } \\
\text { [25] }\end{array}$ & $\begin{array}{c}\text { Both sexes } \\
\text { (CT: } 59, \text { CG: } 61)\end{array}$ & 26 weeks & $\begin{array}{l}3 \mathrm{x} / \text { week } \\
\text { AT: progressing from } 15 \text { to } 20 \mathrm{~min} \text { at } 60 \% \mathrm{HR}_{\max } \text { to } \\
45 \mathrm{~min} \text { at } 75 \% \mathrm{HR}_{\max } \\
\text { RT: } 2 \text { to } 3 \text { sets of } 7 \text { to } 9 \mathrm{RM}(2 \text { groups of } 7 \text { exercises } \\
\text { alternatedly performed, m.m.g.) }\end{array}$ & $\begin{array}{l}\text { Significant alteration: } \downarrow 0.95 \% \text { in } \\
\text { comparison to pre-training }\end{array}$ \\
\hline
\end{tabular}

AT: aerobic training, RT: resistance training, CT: combined training group, CG: control group, n: number of participants, RM: maximum repetitions, 1RM: one maximum repetition test, rep: repetitions, $\downarrow$ : reduction, $\mathrm{HR}_{\text {max }}$ : maximum heart rate, $\mathrm{HR}_{\mathrm{res}}$ : reserve heart rate, $\mathrm{HR}_{\mathrm{LT}}$ : heart rate at lactate threshold, $\mathrm{HbAlc:} \mathrm{glycated} \mathrm{hemoglobin,} \mathrm{VO}_{2 \text { peak: }}$ peak oxygen consumption, $\mathrm{VO}_{2 \max }$ : maximal oxygen consumption. \%HbAlc: reduction in percentage, m.m.g.: main muscle groups.

significant alterations in $\mathrm{HbAlc}$ levels did not perform progression of the trainings, whereas Tessier et al. [12] carried out a slight increase in the intensity of the aerobic component. As these studies performed medium-term interventions periods of 12 [21] and 16 [12] [13] weeks, we speculate that the lack of training progression seems to be a failure in training prescription, violating the scientific principle of training overload. Also, in order to combine both aerobic and resistance stimuli in the same session, some studies avoid performing long training sessions, and therefore have a limited time available to perform both components (i.e. $20 \mathrm{~min}, 2$ sets). Therefore, it seems that with 12 [21] and 16 [12] [13] weeks of follow-up, the training dosage of these interventions seemed to be low to elicit HbAlc adaptations. It is also important to highlight that another possible explanation for the absence of alterations in the study of Cuff et al. [13], is that the participants had low baseline levels of $\mathrm{HbA1c}$, which limited their amplitude of improvement in this outcome.

\subsection{Weekly Frequency}

The importance of training frequency has been well documented, especially in aerobic training studies. In this direction, a meta-regression analysis conducted by Umpierre et al. [6], evaluating the association between physical training intensity and volume and the changes in HbA1c levels in T2DM patients found that weekly frequency is the main determining factor in the glycaemic control by means of aerobic training for this population. Moreover, it is recommended that aerobic training is performed in at least three days of the week, with no more 
than two consecutive days between training sessions, due to the short duration nature of the improvements in insulin action [3] [4]. On the other hand, for combined training, the association between weekly frequency and glycaemic control is still not elucidated.

Regarding weekly frequency of the selected studies, two of them performed CT with aerobic and resistance trainings performed in the same days, twice a week [19] [20]; eight studies performed resistance and aerobic trainings in the same days, three times per week [12] [13] [14] [16] [17] [21] [23] [25]; one study performed both trainings in the same days, four times per week [22]; one study performed resistance and aerobic trainings in alternated days, being twice a week for each one [15]; one study performed one weekly session of aerobic training, one weekly session of resistance training and two weekly sessions combining both training types in the same session [24]; and one study conducted aerobic training in three weekly sessions and resistance training twice a week [18].

According to ADA [3], physical exercise recommendations for T2DM patients are at least three weekly sessions of aerobic training and two weekly sessions of resistance training. All the interventions performed the minimum recommendation for resistance training. Eleven of the interventions [12] [13] [14] [16] [17] [18] [21] [22] [23] [24] [25] are in accordance with the minimum weekly frequency for aerobic training. Of these, only three studies did not find reductions in HbA1c levels [12] [13] [21]. On the other hand, although the other studies did not reach the minimum weekly frequency recommended for aerobic training [15] [19] [20], all of them found reductions in HbAlc levels. These reductions could have resulted from other interventions characteristics performed, as the three studies performed progressions in volume and/or intensity throughout the interventions, which, according to Fleck and Kraemer [28], can optimize the results, that is, these interventions may have generated new physiological stimuli across the interventions, consequently resulting $\mathrm{HbAlc}$ reductions.

Additionally, it is important to highlight that the studies which found the most expressive reductions in $\mathrm{HbAlc}$ levels (decreases of $0.95 \%$ to $1.21 \%$, Table 1) were those conducting both aerobic and resistance trainings in the same days, in three and four weekly sessions [14] [19] [23] [25]. All these studies had progression of the training variables. Moreover, in two of these interventions [23] [25] a significant volume of exercises were performed for the resistance training component (14 exercises each, with 3 sets of 8 - 12 sets of 7 - 9 maximum repetitions, respectively), which is in accordance with the results found in the meta-regression of Umpierre et al. [6], attributing the weekly volume of resistance training exercises to the $\mathrm{HbAlc}$ reductions resulting from $\mathrm{CT}$.

\subsection{Duration and Intensity}

Over the years, well designed studies have been attributing the success of physical training interventions not only to the modality but also to some training va- 
riables. In a meta-analysis conducted by Boulé et al. [9], physical training intensity was associated to reductions in HbA1c levels in a greater extent than training volume. Later, Umpierre et al. [5] demonstrated that weekly duration was fundamental for $\mathrm{HbAlc}$ reductions, independently of the training modality. On the other hand, Umpierre et al. [6] showed that in aerobic training the only training variable associated to glycaemic reduction was weekly frequency, whereas any strength training variable was associated to glycaemic reduction and, in $\mathrm{CT}$, only the number of sets in the resistance component presented this association.

Regarding the management of AT duration and intensity for T2DM patients, it is recommended that is must be performed for at least 150 minutes per week with moderate to high intensity, disseminated into three weekly sessions, with no more than two consecutive days between training sessions [4]. Of the 14 studies selected, four did not report session durations [13] [18] [20] [21] and only three studies did not find reductions in HbA1c levels [12] [13] [21]. Thus, we verified that the reality of these studies which reported the training durations does not contemplate ADA [3] guidelines for aerobic training duration. These findings corroborate the meta-regression analysis of Umpierre et al. [6], which did not evidence association between $\mathrm{AT}$ duration and $\mathrm{HbA} 1 \mathrm{c}$ levels reduction resulting from $\mathrm{CT}$, being the RT number of sets the variable associated to glycaemic control through this training modality. Faced with that, it becomes necessary a further reflection about training guidelines for T2DM people, as other training characteristics (and not the training duration of 150 minutes) may be attributed to reductions in $\mathrm{HbA} 1 \mathrm{c}$ levels of this population.

We believe that finding positive results with weekly durations shorter than 150 minutes in AT can positively impact on training adherence, which is fundamental for the success of physical training interventions. With the advancement of modern and busy life, with often long working hours, in which people have increasingly less free time to exercise, it is important that physical training is time-efficient to help individuals to reach their goals and keep maintaining an active and healthy life.

In the present review, the studies adopted different intensity markers. In AT, seven studies prescribed training intensity using percentages of maximum heart rate $\left(\mathrm{HR}_{\max }\right)$ [12] [15] [16] [22] [23] [24] [25], three used percentages of heart rate reserve $\left(\mathrm{HR}_{\mathrm{res}}\right)$ [13] [14] [17], three used percentages of maximum oxygen consumption $\left(\mathrm{VO}_{2 \max }\right)$ [18] [19] [20] and one study conducted it through the heart rate corresponding to lactate threshold $\left(\mathrm{HR}_{\mathrm{LT}}\right)[21]$. Of the selected studies, those that used the intensities prescribed between 60 and $75 \%$ of $\mathrm{HR}_{\max }$ (15 to 45 $\mathrm{min} /$ session) [25], $70 \%$ to $75 \%$ of $\mathrm{HR}_{\max }$ (25 to $45 \mathrm{~min} / \mathrm{session}$ ) [23], $70 \%$ to $80 \%$ of $\mathrm{VO}_{2 \max }$ (40 min/session) [19], and the intensities between $40 \%$ and $80 \%$ of $\mathrm{HR}_{\text {res }}$ (30 $\mathrm{min} /$ session) [14] for AT were those that found the greater reductions in HbAlc levels.

It is important to highlight that, among the articles included in the present re- 
view, 10 of them [12] [15] [16] [18] [19] [20] [22] [23] [24] [25] used percentages of $\mathrm{HR}_{\max }$ and $\mathrm{VO}_{2 \max }$ for $\mathrm{AT}$ prescription. It is well known that the exercise performed in a certain percentage of $\mathrm{VO}_{2 \max }$ or $\mathrm{HR}_{\max }$ can induce different physiologic responses for different individuals, and that submaximal parameters as anaerobic threshold are better indicators for aerobic training prescription [29]. Moreover, the anaerobic threshold determination method through heart rate deflexion point, which has low cost, easy application and was associated to the second ventilatory threshold in T2DM patients [30], was not used in any of the reviewed studies. Therefore, we emphasize that there are other possibilities with greater metabolic precision, which have not been used in studies with T2DM patients.

In relation to the management of RT intensity, seven studies performed it by means of percentages of one repetition maximum (1RM) test [14] [15] [17] [19] [20] [22] [24], two used 7 to 9 maximum repetitions [16] [25], one adopted 10 to 12 maximum repetitions [18], one used 8 to 12 maximum repetitions [23] and three studies did not specify the way that RT intensity was conducted [12] [13] [21]. Most of the studies maintained the intensity fixed throughout all the interventions periods, whereas five studies progressed RT intensities at some point of the intervention [12] [15] [17] [20] [23]. Of these, only one [12] did not find significant alterations in HbAlc levels. Regarding the best results found [14] [19] [23] [25], the intensities between 7 to 9 maximum repetitions, 8 to 12 maximum repetitions, $80 \%$ of $1 \mathrm{RM}$ and from $40 \%$ to $60 \%$ of $1 \mathrm{RM}$ were respectively used.

\subsection{Number of Exercises in RT}

The selected studies for the present review adopted different numbers of exercise for the resistance training component of the CTs. The number varied from two exercises (one for upper and one for lower limbs) [17], six exercises for the big muscle groups [14] [22] to fourteen exercises [23] [24] [25], also for large muscle groups.

Although the ADA indications are of 8 to 12 resistance exercises prioritizing the big muscle groups [3] [4], an analysis of this parameter in the reviewed studies demonstrates that this is not a determining factor for glycaemic control, because studies with similar number of exercises induced different responses. It becomes clear by analyzing the number of RT exercises in the four studies with the best results in $\mathrm{HbAlc}$, because whereas Stegen et al. [25] and Larose et al. [23] performed 14 exercises in their interventions, Balducci et al. [14] performed six exercises and Balducci et al. [19] performed five exercises. Thus, we believe that other training variables, as intensity, number of sets and repetitions may have greater relevance in the combined training programs structuring, as well as training variables progression, aiming to periodically induce new physiological adaptations in T2DM individuals, and consequently the glycaemic control for this population. 


\subsection{Order of the Modalities}

In the reviewed studies, different manners of performing the order of resistance and aerobic trainings were applied. Of these, six studies [13] [14] [16] [19] [22] [25] performed AT before RT in the same training sessions; three studies [12] [17] [21] conducted both training modalities in the same session, in circuit; one study [15] performed AT and RT in separate days; one study [24] used one weekly session for AT, one weekly session for RT and two weekly sessions with both training types, without specifying the order; one study [23] allowed the participants to choose the training order; whereas the other studies [18] [20] did not report the training order. Of the four studies that showed the best results in the glycaemic control, three of them performed AT before RT in the same sessions [14] [19] [25] and one of them allowed the participants to choose the order [23].

CT has been widely explored in the literature, and in this context, the interference effect has also emerged, which explains that the expected results from RT suffer interference of AT, that is, the strength development is impaired when AT precedes RT [31], whereas cardiorespiratory fitness does not suffer the same impairment when it is performed after RT [32]. The order effect has not yet been investigated in T2DM population, therefore, there is a doubt whether the training order could interfere in the interventions results, if some order could maximize glucose uptake and possibly result in a better glycaemic control. In addition, we also emphasize that the training order could be investigated regarding training adherence, which is a very important issue to be considered in the clinical population. Besides the training order be pre-established by physical exercise professionals, there is also the possibility of the patient to choose the order, which could also positively influence on adherence to interventions.

\subsection{Comparisons between CT with AT and/or RT}

In the present review, three studies compared CT with AT [13] [17] [19], one study compared CT with RT [23], and five studies compared CT with both aerobic and resistance trainings separately performed [16] [18] [21] [24] [25]. Of these, only one study did not find significant results in $\mathrm{HbA1c}$ levels in both aerobic and resistance trainings [13].

In the intervention conducted by Lambers et al. [17], comparing AT and CT groups, only CT found $\mathrm{HbAlc}$ reductions, whereas the other studies [16] [18] [19] [21] [24] [25] found greater reductions in HbAlc levels with CT in comparison to other groups that performed AT or RT alone. These results show that every time that CT was compared with AT or RT isolated, CT induced greater results. Other important issue is that in the study of Church et al. [18] performed with three intervention groups (AT, RT and CT) only CT group participants underwent reduction in $\mathrm{HbAlc}$ values. Although this decrease was not very expressive, this reduction was significant, showing that in a long training period (52 weeks), in which there was not progression of the training variables, it seems 
that only the combination of aerobic and resistance stimuli was able to sustain the gains reached in the first months of training.

\section{Conclusions}

Faced with the studies selected for the present review, we can conclude that combining aerobic and resistance trainings can induce a better glycaemic control than these interventions performed alone. However, the great number of different methods adopted in the several studies limits our ability to provide the optimal exercise strategy for T2DM management.

Despite this, faced with the characteristics of the included studies, we can state that the interventions that induced the greater reductions in HbAlc levels had the weekly frequency from three to four times a week (with AT and RT performed in the same days). Regarding aerobic training intensity and duration, the best results were shown with the interventions that used training prescription with durations between 30 and 45 minutes per session, with intensities among $60 \%$ and $80 \%$ of maximal parameters. In the resistance component, the results with sets of 8 to 12 repetitions in the intensities of $80 \%$ and $60 \%$ of $1 \mathrm{RM}$, respectively, or in the same number or repetitions prescribed by maximum repetitions, with exercises for the big muscle groups, were highlighted. We emphasize that sedentary patients can initiate training programs in volume intensities below the indicated ones, and continuously increase it throughout the interventions, by means of progression of the training variables.

We believe that future studies should investigate CT specific characteristics, as its performance in alternate days (AT and RT) versus in the same session, as well as the order of accomplishment of aerobic and resistance modalities.

\section{References}

[1] Whiting, D.R., Guariguata, L., Weil, C. and Shaw, J. (2011) IDF Diabetes Atlas: Global Estimates of the Prevalence of Diabetes for 2011 and 2030. Diabetes Research and Clinical Practice, 94, 311-321. https://doi.org/10.1016/j.diabres.2011.10.029

[2] International Diabetes Federation (IDF). (2015) Diabetes Atlas. 7th Edition, 1-136.

[3] American Diabetes Association. (2017) Standards of Medical Care in Diabetes. Diabetes Care, 40, S1-S104.

[4] Colberg, S.R., Sigal, R.J., Yardley, J.E., Riddel, M.C., Dunstan, D.W., Dempsey, P.C., Horton, E.S. Castorino, K. and Tate, D.F. (2016) Physical Activity/Exercise and Diabetes: A Position Statement of the American Diabetes Association. Diabetes Care, 39, 2065-2079. https://doi.org/10.2337/dc16-1728

[5] Umpierre, D., Ribeiro, P., Kramer, C., Leitão, C., Zucatti, A., Azevedo, M., Gross, J., Ribeiro, J. and Schaan, B. (2011) Physical Activity Advice Only or Structured Exercise Training and Association with HbA1c Levels in Type 2 Diabetes. Journal of the American Medical Association, 305, 1790-1799. https://doi.org/10.1001/jama.2011.576

[6] Umpierre, D., Ribeiro, P.A.B., Schaan, B.D. and Ribeiro, J.P. (2013) Volume of Supervised Exercise Training Impacts Glycaemic Control in Patients with Type 2 Di- 
abetes: A Systematic Review with Meta-Regression Analysis. Diabetologia, 56, 242-251. https://doi.org/10.1007/s00125-012-2774-Z

[7] Oliveira, O., Simões, M., Carvalho, J. and Ribeiro, J. (2012) Combined Exercise for People with Type 2 Diabetes Mellitus: A Systematic Review. Diabetes Research and Clinical Practice, 98, 187-198. https://doi.org/10.1016/j.diabres.2012.08.004

[8] Stratton, I.M., Adler, A.I., Neil, A.W., Mathews, D.R., Manley, S.E., Cull, C.A., Hadden, D., Turner, R.C. and Holman, R.R. (2000) Association of Glycaemia with Macrovascular and Microvascular Complications of Type 2 Diabetes (UKPDS 35): Prospective Observational Study. BMJ, 321, 405-412. https://doi.org/10.1136/bmj.321.7258.405

[9] Boulé, N.G., Haddad, E., Kenny G.P., Wells, G.A. and Sigal, R.J. (2001) Effects of Exercise on Glycemic Control and Body Mass in Type 2 Diabetes Mellitus. JAMA, 286, 1218-1227. https://doi.org/10.1001/jama.286.10.1218

[10] Snowling N.J. and Hopkins, W.G. (2006) Effects of Different Modes of Exercise Training on Glucose Control and Risk Factors for Complications in Type 2 Diabetic Patients: A Meta-Analysis. Diabetes Care, 29, 2518-2527.

https://doi.org/10.2337/dc06-1317

[11] Schwingshackl, L., Missbach, B., Dias, S., König, J. and Hoffmann, G. (2014) Impact of Different Training Modalities on Glycaemic Control and Blood Lipids in Patients with Type 2 Diabetes: A Systematic Review and Network Meta-Analysis. Diabetologia, 57, 1789-1797. https://doi.org/10.1007/s00125-014-3303-z

[12] Tessier, D., Menard, J., Fulop, T., Ardilouze, J., Roy, M. and Dubuc, N. (2000) Effects of Aerobic Physical Exercise in the Elderly with Type 2 Diabetes Mellitus. Archives of Gerontology and Geriatrics, 31, 121-132. https://doi.org/10.1016/S0167-4943(00)00076-5

[13] Cuff, D.J., Meneilly, G.S., Martin, A., Ignaszewski, A., Tildesley, H.D. and Frohlich, J.J. (2003) Effective Exercise Modality to Reduce Insulin Resistance in Women with Type 2 Diabetes. Diabetes Care, 26, 2977-2982. https://doi.org/10.2337/diacare.26.11.2977

[14] Balducci, S., Leonetti, F., Di Mario, U. and Falluca, F. (2004) Is a Long-Term Aerobic Plus Resistance Training Program Feasible for and Effective on Metabolic Profiles in Type 2 Diabetic Patients? Diabetes Care, 27, 841-842. https://doi.org/10.2337/diacare.27.3.841

[15] Tokmakidis, P., Zois, E., Volaklis, A. and Touvra, A. (2004) The Effects of a Combined Strength and Aerobic Exercise Program on Glucose Control and Insulin Action in Women with Type 2 Diabetes. European Journal of Applied Physiology, 92, 437-442. https://doi.org/10.1007/s00421-004-1174-6

[16] Sigal, R., Kenny, P., Boulé, N., Wells, G., Prud'homme, D., Fortler, M., Reid, R.D., Tulloch, H., Coyle, D., Phillips, P., Jennings, A. and Jaffey, J. (2007) Effects of Aerobic Training, Resistance Training, or Both on Glycemic Control in Type 2 Diabetes. Annals of Internal Medicine, 147, 357-371. https://doi.org/10.7326/0003-4819-147-6-200709180-00005

[17] Lambers, S., Laethem, C.V., Acker, K.V. and Calders, P. (2008) Influence of Combined Exercise Training on Indices of Obesity, Diabetes and Cardiovascular Risk in Type 2 Diabetes Patients. Clinical Rehabilitatio, 22, 483-492. https://doi.org/10.1177/0269215508084582

[18] Church, S., Blair, N., Cocreham, S., Neil, J., Johnson, W., Kramer, K., Mikus, C., Myers, V., Nauta, M., Rodarte, R., Sparks, L., Thompson, A. and Earnest, C.P. (2010) Effects of Aerobic and Resistance Training on Hemoglobin A1c Levels in Pa- 
tients with Type 2 Diabetes: A Randomized Controlled Trial. JAMA, 304, 2253-2264. https://doi.org/10.1001/jama.2010.1710

[19] Balducci, S., Zanuso, S., Nicolucci, A., Fernando, F., Cavallo, S., Cardelli, P., Falluca, S., Alessi, E., Letizia, C., Jimenez, A., Falluca, F. and Pugliese, G. (2010) Anti-Inflammatory Effect of Exercise Training in Subjects with Type 2 Diabetes and the Metabolic Syndrome Is Dependent on Exercise Modalities and Independent of Weight Loss. Nutrition, Metabolism \& Cardiovascular Diseases, 20, 608-617. https://doi.org/10.1016/j.numecd.2009.04.015

[20] Fatone, C., Guescini, M., Balducci, S., Battistoni, S., Settequattrini, A., Pippi, R., Stocchi, L., Mantuano, M., Stocchi, V. and Feo, P. (2010) Two Weekly Sessions of Combined Aerobic and Resistance Exercise Are Sufficient to Provide Beneficial Effects in Subjects with Type 2 Diabetes Mellitus and Metabolic Syndrome. Journal of Endocrinological Investigation, 33, 489-495. https://doi.org/10.1007/BF03346630

[21] Jorge, M.L., De Oliveira, V.N., Resende, N.M., Paraiso, L.F., Calixto, A., Diniz, A.L., Resende, E.S., Ropelle, E.R., Carvalheira, J.B., Espindola, F.S., Jorge, P.T. and Geloneze, B. (2011) The Effects of Aerobic, Resistance, and Combined Exercise on Metabolic Control, Inflammatory Markers, Adipocytokines, and Muscle Insulin Signaling in Patients with Type 2 Diabetes Mellitus. Metabolism, 60, 1244-1252. https://doi.org/10.1016/j.metabol.2011.01.006

[22] Touvra, A., Volaklis, A., Spassis, T., Zois, C., Douda, T., Kotsa, K. and Tokmakitis, S.P. (2011) Combined Strength and Aerobic Training Increases Transforming Growth Factor- $\beta 1$ in Patients with Type 2 Diabetes. Hormones, 10, 125-130. https://doi.org/10.14310/horm.2002.1302

[23] Larose, J., Sigal, R.J., Khandwala, F. and Kenny, G.P. (2012) Comparison of Strength Development with Resistance Training and Combined Exercise Training in Type 2 Diabetes. Scandinavian Journal of Medicine \& Science in Sports, 22, e-45-44. https://doi.org/10.1111/j.1600-0838.2011.01412.x

[24] Kadoglou, N.P., Fotiadis, G., Kapelouzou, A., Kostakis, A., Liapis, C.D. and Vrabas, I.S. (2013) The Differential Anti-Inflammatory Effects of Exercise Modalities and Their Association with Early Carotid Atherosclerosis Progression in Patients with Type 2 Diabetes. Diabetic Medicine, 30, e-41-50. https://doi.org/10.1111/dme.12055

[25] Stegen, S., Sigal, R., Kenny, G., Farah, K., Yard, B., Heer, E., Baelde, H., Peersman, W. and Derave, W. (2015) Aerobic and Resistance Training Do Not Influence Plasma Carnosinase Content or Activity in Type 2 Diabetes. American Journal of Physiology Endocrinology and Metabolism, 309, E663-E669.

https://doi.org/10.1152/ajpendo.00142.2015

[26] Duclos M., Oppert, J.M., Verges, B., Coliche, V., Gautier, J.F., Guezennec, Y., Reach, G. and Strauch, G. (2013) Physical Activity and Type 2 Diabetes. Recommendations of the SFD (Francophone Diabetes Society) Diabetes and Physical Activity Working Group. Diabetes \& Metabolism, 39, 205-216. https://doi.org/10.1016/j.diabet.2013.03.005

[27] Sumita, N.M. and Andriolo, A. (2008) Glycated Hemoglobin Importance in Diabetes Mellitus Control and in the Risk Assessment of Chronic Complications. Jor nal Brasileiro de Patologia e Medicina Laboratorial, 44, 174-197.

[28] Fleck, S.J. and Kraemer, W.J. (2004) Designing Resistance Training Programs. 3rd Edition, Human Kinetics, Champaign, IL.

[29] Meyer, T., Lucia, A., Earnest, C.P. and Kindermann, W. (2005) A Conceptual Framework for Performance Diagnosis and Training Prescription from Submaximal Gas Exchange Parameters-Theory and Application. International Journal of Sports Med- 
icine, 26, s38-48. https://doi.org/10.1055/s-2004-830514

[30] Delevatti, R.S., Kanitz, A.C., Alberton, C.L., Pantoja, P.D., Marson, E.C., Pinho, C.D.F., Lisboa, S.C., Bregagnol, L.C. and Kruel, L.F.M. (2015) Heart Rate Deflection Point as an Alternative Method to Identify the Anaerobic Threshold in Patients with Type 2 Diabetes. Apunts Medicina de I Esport, 50, 123-128.

https://doi.org/10.1016/j.apunts.2015.05.001

[31] Cadore, E.L., Pinto, R.S., Pinto, S.S., Alberton, C.L., Correa, C.S., Tartaruga, M.P., Silva, E.M., Almeida, A.P.V., Trindade, G.T. and Kruel, L.F.M. (2011) Effects of Strength, Endurance, and Concurrent Training on Aerobic Power and Dynamic Neuromuscular Economy in Elderly Men. The Journal of Strength \& Conditioning Research, 25, 758-766. https://doi.org/10.1519/JSC.0b013e318207ed66

[32] Cadore, E.L., Pinto, R.S., Lhullier, F.L.R., Correa, C.S., Alberton, C.L., Pinto, S.S., Almeida, A.P.V., Tartaruga, M.P., Silva, E.M. and Kruel, L.F.M. (2011) Physiological Effects of Concurrent Training in Elderly Men. The Journal of Strength \& Conditioning Research, 31, 689-697. 